\title{
English Learning System Design for College Students Personalized English Grammar Check and Diagnosis
}

\author{
https://doi.org/10.3991/ijet.v13i04.8467 \\ Dandan Pan $\left.{ }^{\bowtie}\right)$, Hongzhi Zhou \\ Fuyang Normal University, Fuyang, China \\ Wupandan@163.com
}

\begin{abstract}
The development of computer technologies help enrich the content of English education and provide more convenience for English learning. English grammar is one of the basic elements and affects the expression and reception in English listening, speaking, reading and writing directly. How a student masters English grammar has a critical impact on his or her overall English level. This paper attempts to achieve personalized check and diagnosis of college students' English grammar. by integrating relevant computer theories and learning theories. With the help of Visual Studio and SQL computer technology, we can achieve functional design and database design for personalized grammar check and diagnosis for both learning and teaching. The paper also completes the design of the question bank, learning feature database and user feature database Computer-technology-based personalized English grammar check and diagnosis system for college students designed and implemented in this paper can help students grasp English grammatical rules better, improve their grammar test and application abilities and increase their interest in English learning, thus, it has a certain practical value in the college English grammar teaching and learning.
\end{abstract}

Keywords-computer learning system, English teaching, English grammar, learning theory, personalized check and diagnosis

\section{Introduction}

\subsection{Applying the styles to an existing paper}

Language, as a discipline, has its own laws and rules to follow, while grammar as the inherent laws of language plays a very important role in the cohesion of sentences, lexical collocation and semantic expression [1]. Due to cultural differences between China and the West, there are also certain differences between English and Chinese grammars. However, except for students majoring in English, there is hardly any grammar courses to instruct and improve students' grammar in English teaching in China; and thus grammar has become a weak point for most English learners in China [2] and seriously hindered students' English level and language use and also constrained their English self-learning abilities. 
The popularity of computer and network has greatly improved the level of information technology applied in colleges and universities in China. It is no longer a new thing to study English with the help of computer technology and network [3]. A personalized grammar check and diagnosis system specifically to address the grammar problems of Chinese students can not only teach students according to their different English grammar levels, but also enable them to prepare appropriate learning materials to train them on specific areas. During the learning process, students can check and diagnose their own English grammar levels in the system and also improve their weak point using the materials provided in the system [4].

Based on the above ideas, this paper first introduces Visual Studio and SQL, which serve as the technical support for system interface and database design, and then gives a brief introduction to the behaviorism, cognitionism and constructivism learning theories, which serve as the learning theory basis for the system [5]. Then, through the system requirement analysis and feasibility analysis from the perspectives of teachers, students and administrator, and analysis of students' functions and teachers' functions, and design of the database functions, this paper completes the preparations for the system design [6]. Finally, according to the appropriate technical scheme, it completes the design of the computer-based personalized English grammar check and diagnosis system for college students and achieves relevant functions to meet the needs of users. This system provides scientific diagnosis methods and highly suitable learning materials to help students learn and improve their English grammar, and at the same time reduces English teachers' workload and improve students' English learning efficiency and learning initiatives greatly.

\section{Overview of computer technologies and learning theories}

\subsection{Computer technologies}

Visual studio C\#. This system chooses Visual Studio C\# as the programming language [7]. Visual C\# (C Sharp) is a kind of object-oriented design language developed by Microsoft. With concise syntax and type safety, it has become another classic language launched by Microsoft after the $\mathrm{C}$ language and $\mathrm{C}++$ language. While keeping the good merits of the $\mathrm{C}$ language and $\mathrm{C}++$ language, $\mathrm{C} \#$ has also made some innovations and adopted a simple and easily understandable syntax [8]. The C\# language system is built on the. NET framework. Compared with the traditional $\mathrm{C} / \mathrm{C}++$ language, $\mathrm{C} \#$ has a lot of merits welcomed by programmers, such as: fully automated memory management mechanism, convenient regular expression, powerful reflection technology and easy interaction with other programming languages. According to a survey on over 20 foreign language teachers who have been working in Fuyang Normal College for nearly 5 years, most English teachers attended the C\# courses in their undergraduate stage or have passed the national computer test Level II through selfstudy, besides, the school HR department would also provide pre-job training on relevant teaching skills, so for most English teachers, it would not be a difficult tech- 
nical problem, and most of them should be able to carry out English teaching through the application of the C\# language.

SQL Server database. This paper uses the SQL server database for the personalized English grammar check and diagnosis database for data management, which is a distributed relational database [9]. The Microsoft SQL Server has the following characteristics:

1. It is built on the client/server system;

2. Graphical management interfaces make a more visual and concise English test system;

3. It has various programming interfaces;

4. It is compatible with other Windows software, which facilitates system expansion and integration;

5. It supports the Web technology, facilitating data release;

6. It supports data warehouse functions, facilitating data storage greatly.

Figure 1 is a schematic diagram of data storage and access in the SQL database [10]. Within the campus network, the administrator, students and teachers can access the system database through independent identity authentication, and outside the network, users can also access the database of the personalized English grammar diagnosis system by identity authentication through the corresponding firewalls.

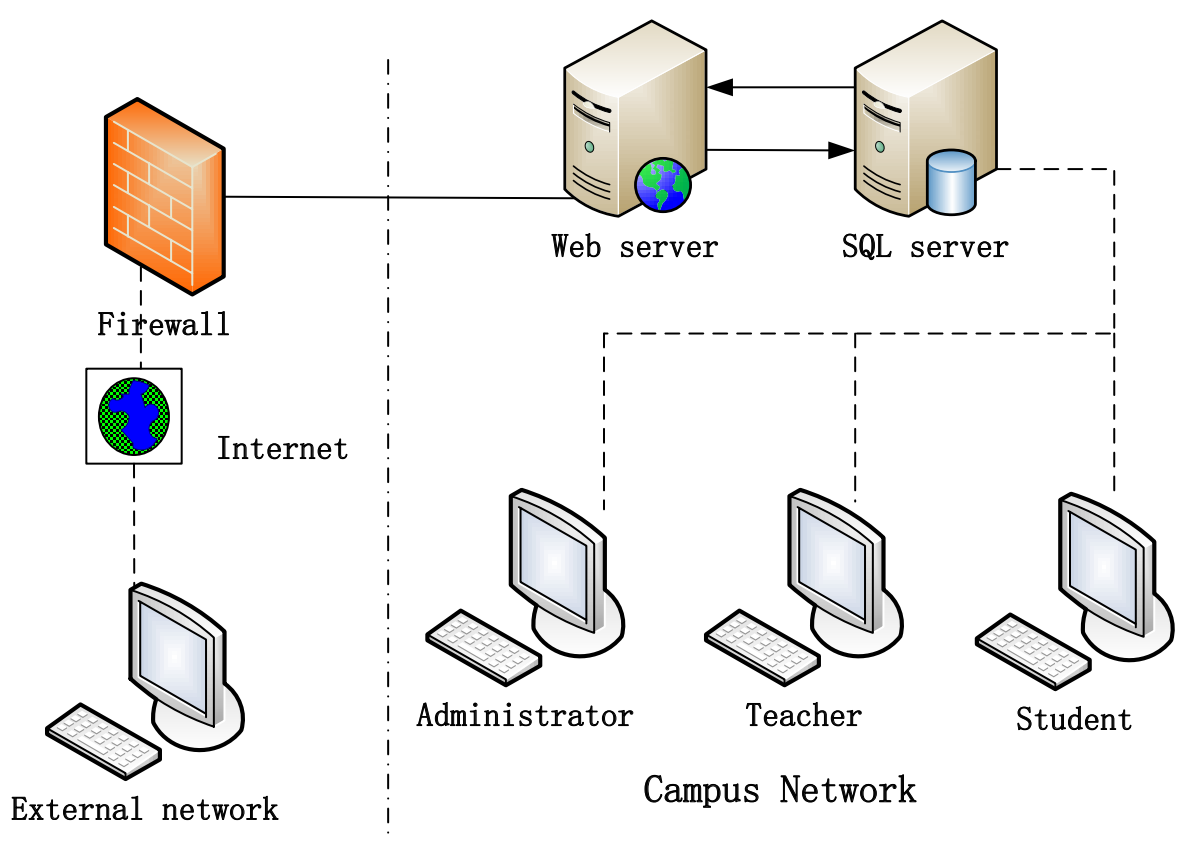

Fig. 1. Schematic diagram of data storage and access in SQL database 


\subsection{Overview of learning theories}

Behaviorism learning theory. Unlike traditional classroom teaching, English teaching based on the network environment is personalized learning, so learners' internal learning drive must be fully considered. The behaviorism learning theory provides the basis and reference for personalized learning. Students can choose their own learning path according to their behavior characteristics and learn with themselves as the center [11].

Cognitionism learning theory. Cognitionism theory holds that human cognition is the result of the interactions between external stimuli and internal mental activities, and English learning is a process where learners carry out effective information processing to external stimuli using their experience based on their own characteristics, needs and preferences [12].

Constructivism learning theory. Constructivism learning theory emphasizes learners as the center and believes that learning is a process where learners construct their own knowledge actively and a process where learners cognize and reconstruct their pre-existing knowledge base. So learning not only includes passive teaching and teaching, but also involves active learning [13].

Based on students' needs, hobbies, initiatives and personalized learning characteristics, this paper attempts to develop a personalized grammar check and teaching system by integrating behaviorism, constructivism and cognitionism, in the hope of providing college English learners with a student-led and teacher-assisted learning platform, building a system that changes classroom-based learning to learner-centered learning and finally achieving English grammar check and diagnosis and helping students evaluate their English grammar skills and correct their mistakes.

\section{System feasibility and requirement analysis}

\subsection{System feasibility analysis}

Despite being a basic element of English learning, English grammar can be easily overlooked, so if teachers and students do not know much about students' English grammar levels, checking and diagnosing grammatical mistakes and knowing how to correct them become very important to improving their English grammar. The feasibility of the personalized grammar check and diagnosis system is analyzed as follows:

Economic feasibility analysis. The system development requires a relatively low costs of hardware and management, so it has very high economic efficiency and can provide English learners with a scientific and efficient way to improve their grammar level.

Technical feasibility analysis. The system uses the Microsoft SQL Server database management system as its back-end database and $\mathrm{C \#}$ as its development language. The above computer software can be developed and run on all operating systems like Windows XP, Window 7 and Window 10, and the requirements of hardware are also low [14], so the computer hardware facilities in normal colleges and universities and students' PCs can meet the operating requirements. 


\subsection{Overall system functional requirement analysis}

\section{Functions for teachers.}

1. Log in the system to supervise students' progress in learning grammar;

2. Supplement and enrich learning materials;

3. Provide constructive advice to improve students' scores in TEM, CET, TOEFL and IELTS exams.

\section{Functions for students.}

1. Check the student's learning record. Through this function, the student is able to know his/her learning progress. The system can record the student's mistakes, and provide customized hints for students on repeated mistakes.

2. Provide the collection of mistakes. The student can check the questions they have provided wrong answers to and understand which part he/she is weak at. The mistake records show how many times a question has been given wrong answers to, proportions of the wrong choices and knowledge corresponding to each of these questions.

3. Participate in the diagnostic test. Diagnostic test is the knowledge test where questions are classified.

4. Intensive training. It is the reinforcement exercises on the knowledge points students are weak at. Through these exercises, students can be gradually familiar with the knowledge and finally achieve an ideal level.

5. Take personalized tests. The student can take personalized tests according to his/her level in each knowledge point, where the test questions are randomly picked by the system. The difficulty of the grammar exercises are in line with the learner's level in that grammatical item, so students will not encounter questions that are too simple or difficult.

Functions for the administrator.

1. Managing users' information, including users' system usage status, users' login status and registration of new users [15].

2. System maintenance and operation. Operational errors are inevitable in the operation of the computer software programmed system, so specialized management personnel need to be assigned to conduct regular system testing and maintenance.

\subsection{System function design}

Functions are implemented according to the system requirements. These functions should be as close as possible to the user's requirements and achieve personalized check and diagnosis of English grammar. Figure 2 shows the whole learning flow chart of the system. 


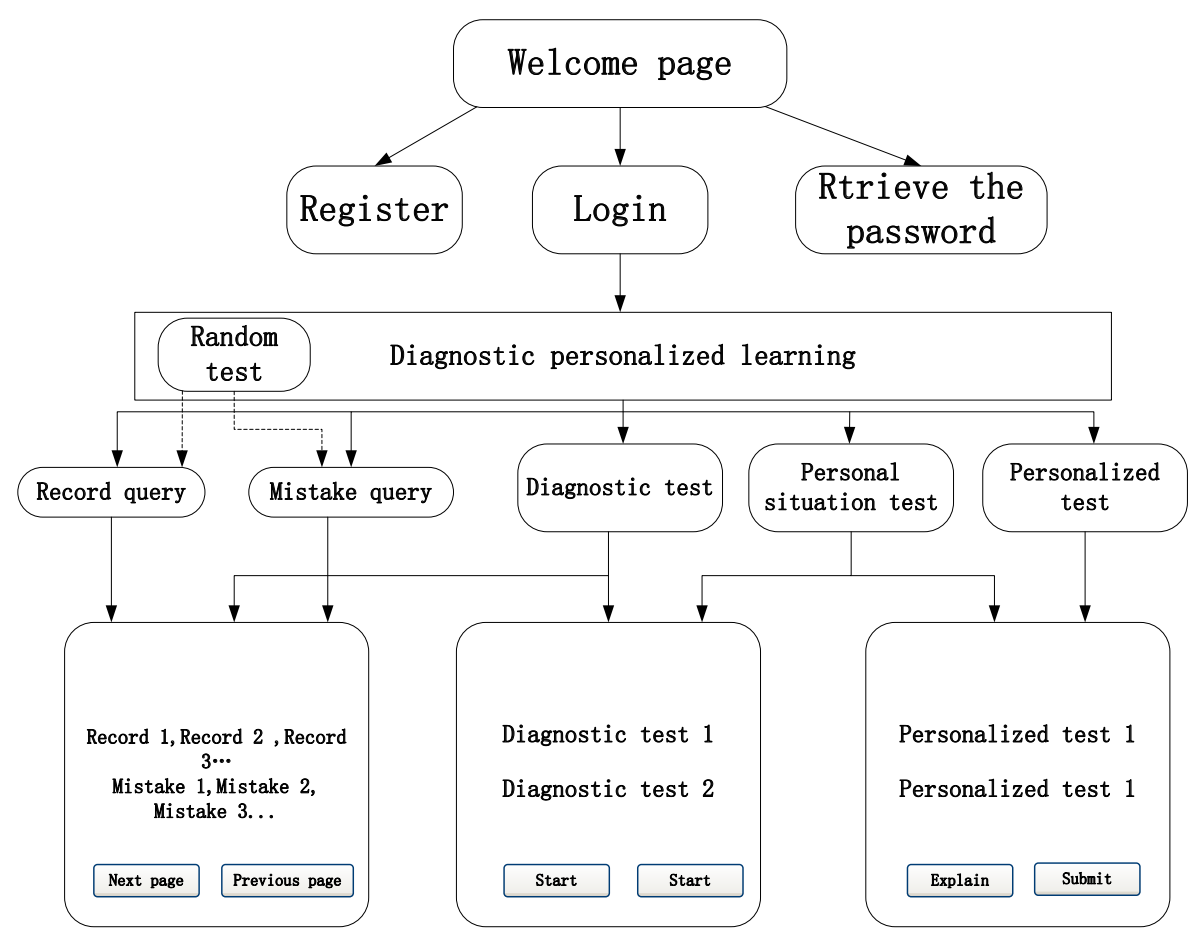

Fig. 2. Overall learning flow chart of the system

Table 1. Examples of learning status in knowledge points

\begin{tabular}{|l|l|l|}
\hline \multicolumn{1}{|c|}{ Knowledge point } & \multicolumn{1}{c|}{ Mastery degree } & \multicolumn{1}{c|}{ Study suggestion } \\
\hline Nouns turn to compound word & Perfect mastery & Not need to continue student \\
\hline Usage of Article 'a' & not master & Intensive training \\
\hline Present continuous tense & basically grasp & Continue training \\
\hline
\end{tabular}

In individual diagnosis, the system diagnoses a student' deficiencies in knowledge according to his/her learning status. Through the previous records of exercises the student has taken, the system would know how well the student grasps the knowledge and give comprehensive rating and comments. The learning status of knowledge points is shown in Table 1.

In the design of teachers' functions, teachers should be able to give explanations to the questions with high error rates. For example, in Test Question 001, the probability that $\mathrm{A}$ is chosen is $20 \%$, that for $\mathrm{B}$ is $70 \%$ and that for $\mathrm{C}$ and $\mathrm{D}$ is $5 \%$, but the correct answer to Question 001 is A, so the students' error rate is up to $80 \%$, and the wrong choices are concentrated in B. This means that students have some problems in this grammar question and require the teacher's guidance. 


\subsection{Database design}

Grammar question bank. The question bank for the computer-based personalized English grammar check and diagnosis system should be designed by the following principles: 1. Obtain the basic probability; 2. Carry out repeated tests; 3.Compare the learning results to understand the patterns frequently. The quality of the question bank is the key to the effectiveness of the system.

The question bank consists of knowledge point tables, question tables and diagnostic test paper tables. ID is used to uniquely identify each knowledge table, question table and test paper table. Figure 3 shows the organization chart of the ID categories.

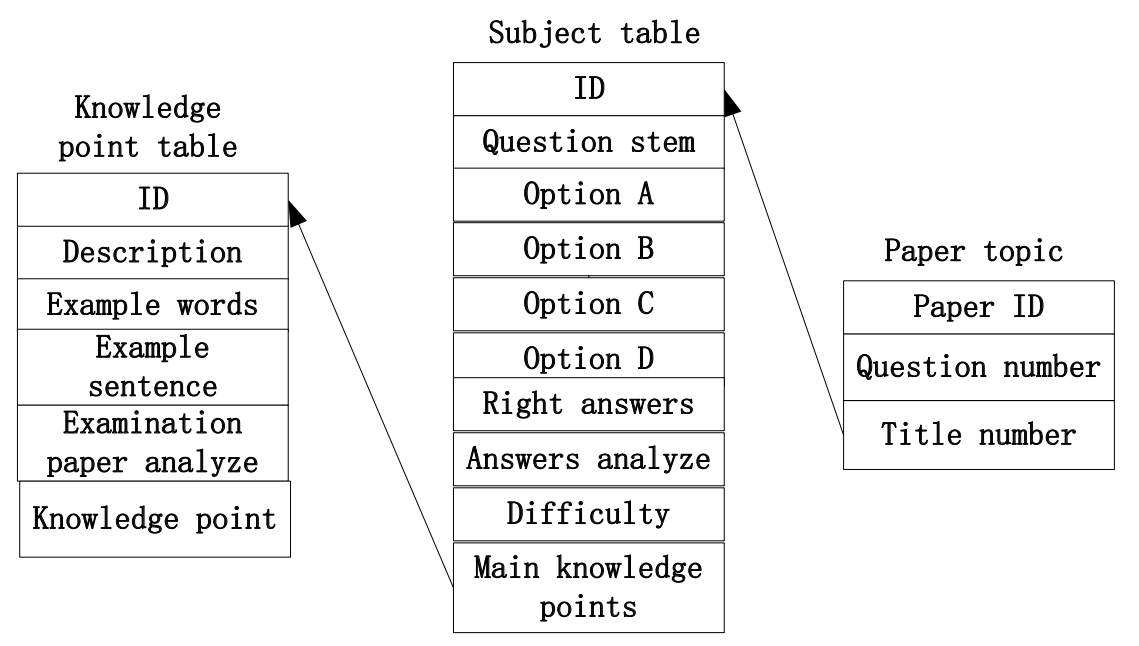

Fig. 3. ID group organization chart

Learning feature database. The student learning feature database consists of exercise record tables, mistake record tables and learning record tables. The organizational structure is similar to that of the question bank. Student number is used as the unique ID. Whenever a student enters the system, the system will record the student's learning status and time.

User feature database. Users are composed of students and teachers, and accordingly, the user feature data base consists of a student information table and a teacher information table. The student information table contains user name and password fields. There are only some minor differences between the teacher table and the student table in terms of authority distribution.

Questions are designed to test the learner's level at each knowledge point and exercises with a difficulty slightly above the test level should be selected. For example, if a student's level rating in plural forms of nouns is 0.24 , then in the random test for the student, the difficulty of the questions regarding this knowledge point should be 0.3 . The integration of behaviorism, constructivism and cognitionism and the latest development theory stimulate students' interest in learning and give them initiatives to think and learn, so their learning efficiencies and effects are improved. 


\section{Implementation of the computer-based personalized English grammar check and diagnosis system for college students}

After the system feasibility, requirement analysis and function design, the author carries out the programming design of the system with the C\# language and the SQL Server database according the principles of stability, efficiency and security.

\subsection{Description of system interfaces}

The author first designs the system login interface, which is mainly used by users to $\log$ in the system and retrieve passwords and to register by new users. Figure 4 shows the login interface of the computer-based personalized English grammar check and diagnosis system.

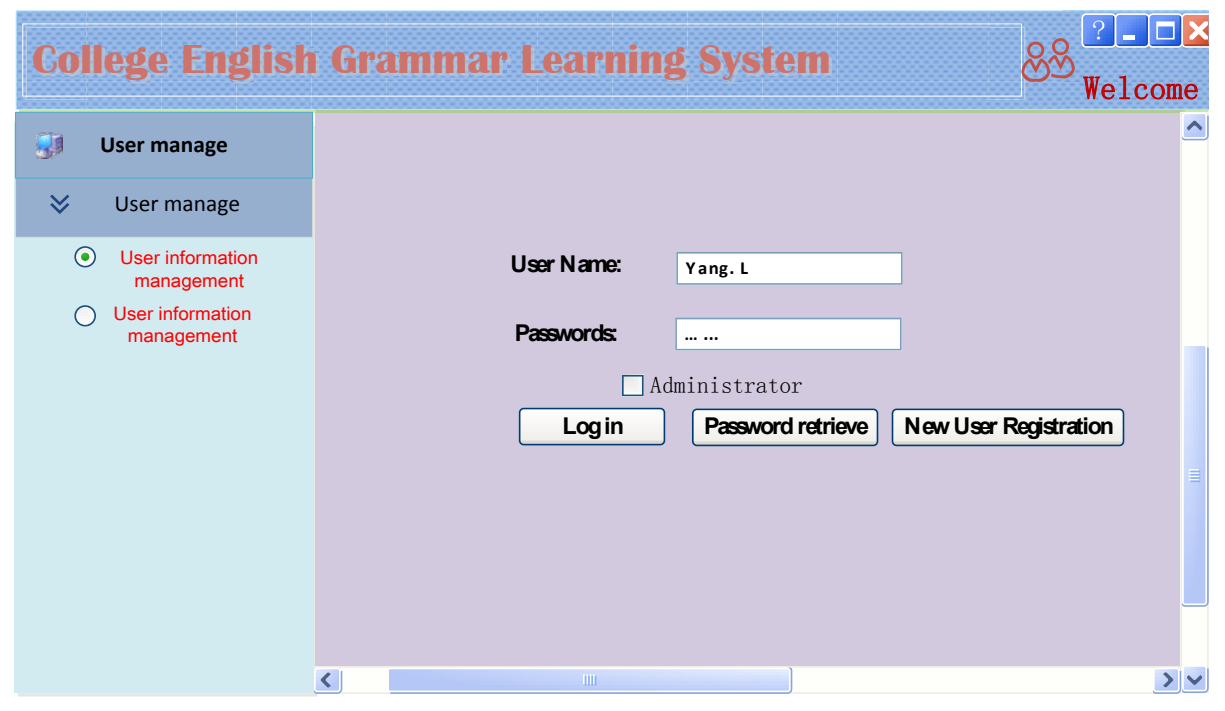

Fig. 4. System login interface

Figure 5 shows the example questions in the personalized grammar test on students in the system. College students can choose the appropriate options in the personalized test bar and then click Submit.

Figure 6 shows the system test record check interface. On this interface, students can review the test they have submitted and completed and at the same time check the correct answers. For those they did not understand, they may add them to the test question database for retest. In this way, they can retrain themselves on the knowledge points they have not grasped. 


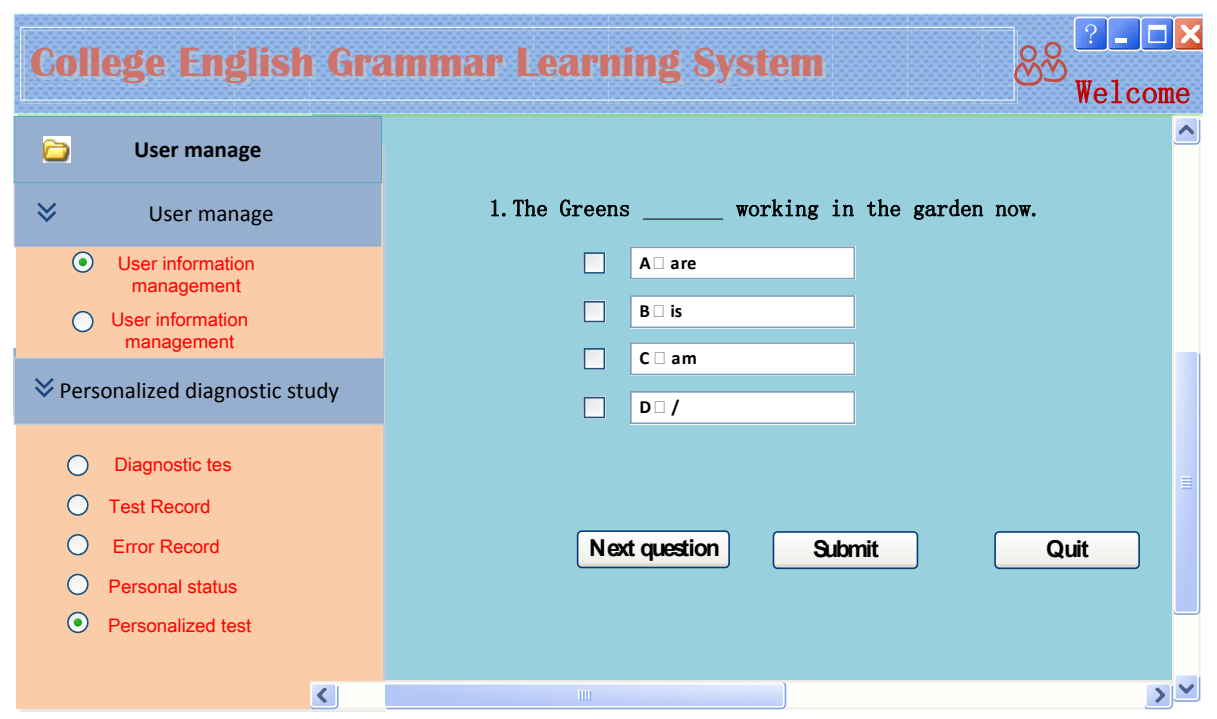

Fig. 5. Example questions

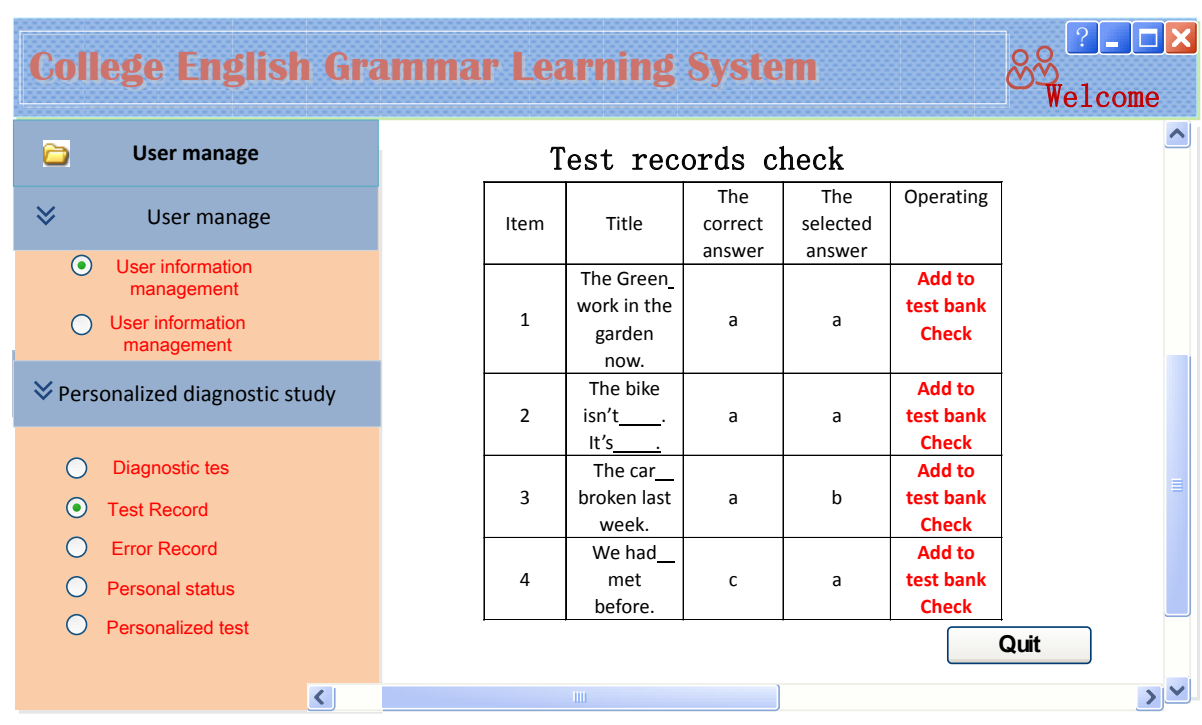

Fig. 6. Test records check interface

System interfaces also include the interfaces for the administrator and those for teachers, which will not be elaborated on in detail. After the system interfaces are designed, the system functions can be basically implemented. This will be a system that can help students understand their own English grammar levels and a platform for teachers to check students' learning status and their obstacles in the process. 


\subsection{English grammar test and check system test}

After the system design is completed, it will undergo a white-box check and a black-box test, respectively to check if the function modules in the system can meet the functional requirements so that problems can be found out at the early stage. The black box test is a test carried out from users' point of view. It tests whether the functions of the software can operate normally based on the functions of the known product. The white box test checks whether the internal actions of the product are carried out in line with the specifications and whether each path in the program operates normally, rather than the functions of the program.

Under the environment where the computer processor is i3, the system memory is $2 \mathrm{~GB}$, the hard drive is $1 \mathrm{~T}$ and the operating system is Window 7, the output results of the following tests are all qualified: user registration and login, I grammar question bank query and addition and test record query, indicating that the system is able to check and test English grammar and that the system test meets requirements.

\section{Conclusions}

In English learning, English grammar is one of the basic elements and directly affects a learner's comprehensive English skills. This paper provides personalized check and diagnosis of student's weak spots in English grammar. After introducing relevant computer technologies and learning theories, it design a personalized English grammar learning system and implements the system functions through feasibility analysis, requirement analysis and functional analysis. The system design is significant in the following aspects:

1. The English grammar learning system based on the C\# language and the SQL Server database is stable and robust, with concise interfaces and safe functions, providing students with specialized solutions to English grammar learning.

2. The system has learning functions for students, assistance functions for teachers and administrative functions for the administrator. With the help of this system, college students with proficient computer skills can carry out self-learning and increase their interest in English learning.

3. English teachers should master the C\# language as soon as possible so that they can apply this technology in their phonetic and listening teaching.

4. The system provides a personalized question bank for each learner to improve their grammar skills. By using this system, students can improve their scores in TEM 4, CET, TOEFL and IELTS exams, so it is very effective in improving students' learning results. 


\section{Acknowledgments}

This work was supported by a grant from Quality Project of Anhui Province of China (No.2015zy143), The excellent talents to support projects in anhui province colleges and universities (No.gxyq 2017159)

\section{$7 \quad$ References}

[1] Schmied J. (2012). Learning English prepositions in the Chemnitz internet grammar, Plos Genetics, Vol. 8, No. 6, pp. e1002770-e1002770.

[2] Murphy R. (2012). English grammar in use: A self-study reference and practice book for intermediate learners of English: With answers and CD-ROMs, Microelectronic Engineering, Vol. 86, No. 4, pp. 718-721.

[3] Friedman E.A. (1984). The wired university: in a growing number of institutions, educators are integrating powerful personal computers and networks into a new learning environment, IEEE Spectrum, Vol. 21, No. 11, 115-120. https://doi.org/10.1109/MSPEC. 1984.6370350

[4] Pothos E.M. (2007). Theories of artificial grammar learning, Psychological Bulletin, Vol 133, No. 2, pp. 227-244. https://doi.org/10.1037/0033-2909.133.2.227

[5] Lieberman M.D., Chang G.Y., Chiao J., Bookheimer S.Y., Knowlton B.J. (2004). An event-related fmri study of artificial grammar learning in a balanced chunk strength design, Journal of Cognitive Neuroscience, Vol. 16, No. 3, pp. 427-438. https://doi.org/10.1162/ 089892904322926764

[6] Jones C.B., Kidner D.B., Luo L.Q., Bundy L.G., Ware J.M. (1996). Database design for a multi-scale spatial information system. International Journal of Geographical Information Science, Vol, 10, No. 8, pp. 901-920. https://doi.org/10.1080/02693799608902116

[7] Hausman K., Tittel E. (2003). Mcad developing and implementing web applications with microsoft visual c\#. net and microsoft visual studio. net exam cram 2 (exam cram 70-315), adobe reader, Physical Review C, Vol. 11, No. 16, pp. 2079-2091.

[8] Mangkulo H.A. (2004). Belajar sendiri aplikasi database menggunakan ado vb 6.0 dan sq1 server 2000, Geomorphology, Vol. 70, No. sp. 3-4, pp. 257-278.

[9] Aguirre Sala J.F. (2004). Sql-retriever 3.0 - visionware's client/server open database connectivity driver provides access to ingres and informix databases - brief article - product announcement. Physics Letters B, Vol. 591, No. 3, pp. 225-228.

[10] Schultz W. (2004). Neural coding of basic reward terms of animal learning theory, game theory, microeconomics and behavioral ecology, Current Opinion in Neurobiology, Vol. 14, No. 2, pp. 139-147. https://doi.org/10.1016/j.conb.2004.03.017

[11] Phillips D.C., Orton R. (1983). The new causal principle of cognitive learning theory: Perspectives on bandura's "reciprocal determinism", Psychological Review, Vol. 90, No. 90, pp. 158-165. https://doi.org/10.1037/0033-295X.90.2.158

[12] Navathe S., Elmasri R., Larson J. (2006). Integrating user views in database design, Computer, Vol. 19, No. 1, pp. 50-62. https://doi.org/10.1109/MC.1986.1663033

[13] Coupal L.V. (2004). Constructivist learning theory and human capital theory: Shifting political and educational frameworks for teachers' ict professional development, British Journal of Educational Technology, Vol. 35, No. 5, pp. 587-596. https://doi.org/10.1111/ j.0007-1013.2004.00415.x 
Paper-English Learning System Design for College Students Personalized English Grammar Check ...

[14] Ozdemir O, Turan M, Turan A.Z, Faki A, Engin A.B. (2009). Feasibility analysis of color removal from textile dyeing wastewater in a fixed-bed column system by surfactantmodified zeolite (smz), Journal of Hazardous Materials, Vol. 166, No. 2-3, pp. 647. https://doi.org/10.1016/j.jhazmat.2008.11.123

[15] Beatrice C., Blasio G.D., Belgiorno G. (2017). Experimental analysis of functional requirements to exceed the $100 \mathrm{kw} / \mathrm{l}$ in high-speed light-duty diesel engines, Fuel, Vol. 207, pp. 591-601. https://doi.org/10.1016/j.fuel.2017.06.112

\section{Authors}

Dandan Pan is a lecturer of College of Information engineering in Fuyang Normal University, Anhui province, China. She works as an English teacher and specializes in English teaching with the help of computer.

Hongzhi Zhou is an associate professor of College of Information engineering in Fuyang Normal University, Anhui province, China. She works as a computer teacher and specializes in computer teaching and program designing.

Article submitted 20 February 2018. Resubmitted 09 March 2018. Final acceptance 25 March 2018. Final version published as submitted by the authors. 